Quebec Cooperative Study

of Friedreich's Ataxia

\title{
Plasma Catecholamines in Friedreich's Ataxia Assayed using High Performance Liquid Chromatography with Electrochemical Detection
}

\author{
A.D. MERKEL, A. BARBEAU
}

\begin{abstract}
Resting levels of plasma norepinephrine, epinephrine and dopamine were determined in 9 patients diagnosed as having Friedreich's Ataxia using a relatively new assay method, HPLC with electrochemical detection. Levels of norepinephrine and dopamine were found to be significantly elevated in patients as compared to controls while epinephrine, though increased, was not significantly higher. These results confirm in most parts previous findings of Pasternak et al. of increased plasma catecholamines and demonstrate the sensitivity and utility of the present method for the routine assay of plasma catecholamines.
\end{abstract}

RÉSUMÉ: Les niveaux plasmatiques, au repos, de norépinephrine, épinéphrine et dopamine furent déterminés chez 9 patients souffrant d'ataxie de Friedreich grâce $\dot{a}$ une méthode relativement nouvelle: la chromatographie liquide à haute performance (HPLC) avec détection électrochimique. Nous avons trouvé des niveaux de norépinéphrine et de dopamine significativement élevés chez les patients comparativement aux témoins. Les niveaux d'épinéphrine, bien qu'élevés, ne l'étaient pas significativement. Ces résultats confirment en grande partie les données de Pasternak et collaborateurs et indiquent de plus que la sensibilité et l'utilité de la présente méthode permettent le dosage routinier des catécholamines plasmatiques.

From the Department of Neurobiology, Clinical Research Institute of Montreal.

Reprint requests for the complete supplement of Friedreich's Ataxia (Phase Three, Part Two) to: Prof. André Barbeau, Clinical Research Institute of Montreal, 110 Pine Avenue West, Montreal, Quebec, Canada, H2W IR 7 .

\section{INTRODUCTION}

One common clinical feature of Friedreich's Ataxia is the presence of cardiomyopathy. The extent and type of cardiac involvement varies among patients and does not necessarily reflect the degree of neurological impairment (Côte et al, 1976; Malo et al, 1976). Indeed, previous reports have indicated that some patients considered to be severely affected demonstrate little cardiac involvement while others, only slightly impaired neurologically, evidence severe cardiac disturbances.

It is known that measurable changes in catecholamine activity often accompany cardiac malfunction (Gazes et al, 1959; Young et al, 1972). Furthermore, at least in animals with hereditary cardiomyopathy, it appears that norepinephrine levels increase prior to the onset of measurable heart disease, suggesting, though not confirming, a causal relationship (Angelakos et al, 1972). In this issue Pasternak et al, (1982) report that both norepinephrine and epinephrine are increased in plasma taken from patients with Friedreich's Ataxia. These changes appear to be related to the degree of ventricular hypertrophy.

The purpose of the present study was to measure free plasma catecholamines in a different group of patients and with a different method to determine the generality of the reported changes. As this study was designed only as a replication, it was considered sufficient to assay plasma catecholamines in patients subjected to only one experimental condition, i.e. in the "resting" or supine position. This experiment was also undertaken to determine the feasibility of using on a routine basis, a recently developed technique for measuring catecholamines in plasma, High Performance Liquid Chromatography with electrochemical detection (LC-ECD). The sensitivity and specificity of this assay have been previously compared to that of the radioenzymatic technique with favorable results (Goldstein et al, 1981; Hjemdahl et al, 1979).

\section{SUBJECTS AND METHODS Plasma Collection}

Nine patients diagnosed as having Friedreich's Ataxia according to the criteria of Geoffroy et al, (1976) and eight healthy volunteers were included in the study. Subjects were instructed to fast for at least 8 hours prior to testing. After the subjects had remained in the supine position for 2 hours, 10 $\mathrm{ml}$ of blood were drawn into chilled polypropylene centrifuge tubes containing $80 \mathrm{mg} / \mathrm{ml}$ EDTA. The blood was centrifuged at $7000 \mathrm{x}$ g for $15 \mathrm{~min}$. at $4^{0} \mathrm{C}$. The plasma was immediately transferred and frozen at $-80^{\circ} \mathrm{C}$ until analyzed.

\section{Reagents}

All reagents were analytical grade and required no further purification. Norepinephrine ( $\mathrm{HBr}$ ) (NE), Dihydroxybenzylamine (HBr) (DHBA), Epinephrine ( $\mathrm{HBr}$ ) (EPI), Dopamine (HC1) (DA), and Trizma Base were purchased from Sigma. Perchloric Acid (70\%), disodium ethylendiaminetetracetic acid (EDTA) and methanol (Omnisolv) were obtained from BDH. Sodium Acetate, citric acid and sodium metabisulfite $\left(\mathrm{Na}_{2} \mathrm{HSO}_{3}\right)$ were from Fisher. Sodium octyl sulfate (SOS) was purchased from ICN. Alumina $\mathrm{HCl}$ 
was obtained from Bioanalytical Systems, but was regenerated according to the method of Anton and Sayre, (1962). All water was dionized, distilled and purified before use.

\section{Apparatus}

The separation of the catecholamines was effected using a Beckman 322 dual piston pump, an Altex \#110 injection valve and a reverse phase ODS $\mathrm{C}_{18}$ Column (4.6 $\mathrm{mm} \times 25 \mathrm{~cm})$ protected by a short precolumn (4.6 $\mathrm{mm} \times 45 \mathrm{~mm})$. The catecholamines were detected by means of a Bioanalytical Systems amperometric detector using a carbon paste working electrode set at a potential of $+0.65 \mathrm{mV}$ vs an $\mathrm{Ag} / \mathrm{AgCl}$ reference electrode. The sensitivity of the detector was adjusted as necessary: 1 na full scale for NE and 0.5 na full scale for EPI, DHBA and DA. Peak heights were recorded on a Shimadzu CRIA integrator.

The mobile phase, consisting of $0.1 \mathrm{M}$ sodium acetate, $0.02 \mathrm{M}$ citric acid, $0.22 \mathrm{mM}$ EDTA and $0.35 \mathrm{mM}$ SOS dissolved in 90:10 v/v $\mathrm{H}_{2} \mathrm{O}$ /Methanol, was filtered through a Millipore filtering device and degassed before use. The eluant was pumped at a rate of $1 \mathrm{ml} / \mathrm{min}$. The use of methanol in conjunction with SOS in the mobile phase provides a means of varying the retention times of the catecholamines. Increasing the concentration of methanol will decrease retention times while increasing the SOS concentration will increase retention times. The exact ratio of methanol to SOS must be optimized for each chromatographic system used.

\section{Extraction of Catecholamines}

Two to three $\mathrm{ml}$ of plasma were pipetted into a $5 \mathrm{ml}$ Reacti-Vial containing $50 \mathrm{mg}$ of acid washed alumina. Twently $\mathrm{ml}$ of $1 \times 10_{-7} \mathrm{M}$ DHBA was added as the internal standard. The catecholamines were absorbed onto the alumina by the addition of $1 \mathrm{ml}$ Tris buffer (1.5 M, pH 8.6) followed by shaking for $15 \mathrm{~min}$. on an Eberbach shaker. The alumina was allowed to settle, the supernatant aspirated off, and the alumina washed 3 times with 1 $\mathrm{ml}$ portions of deionized water. The catecholamines were then desorbed into 2001 of $0.1 \mathrm{M} \mathrm{HClO}_{4}$ containing $4001 \mathrm{Na}_{2} \mathrm{HSO}_{3} /$ liter. To ensure maximum removal of the catecholamines, the acid and the alumina are mixed briefly by swirling and then permitted to stand for exactly $5 \mathrm{~min}$. To avoid injecting particles of alumina, the alumina slurry is transferred to a microfilter (Bioanalytical Systems) and centrifuged at $3000 \mathrm{rpm}$ for $30 \mathrm{sec}$. Then 1001 of the acid supernatant were injected onto the column.

Working standards were provided by adding known quantities of NE, EPI and DA, plus 201 of $1 \times 10_{-7} \mathrm{M}$ DHBA to $2 \mathrm{ml}$ Phosphate Buffer $(\mathrm{pH} 7.0$, $0.1 \mathrm{M}$ ) and carrying it through the assay.

In order to maximize the recovery of the catecholamines from the alumina, several precautions must be observed. First, the absorption characteristics of the alumina decrease with time. As such only a small quantity of acid is prepared at a time (sufficient for 2 weeks) and is stored in a vaccum dessicator. Second, because the buffering capacity of Tris diminishes rapidly, a fresh solution is prepared weekly and refrigerated. Finally, all stock solutions and DHBA solution were prepared fresh every two weeks and were stored frozen in aliquots sufficient for a day's work. The recoveries of NE, EPI and DA averaged $87 \%, 93 \%$ and $91 \%$ respectively.

\section{Calculation}

The assay proved to be linear for all compounds in the ranges tested, i.e. $100-1000 \mathrm{pg}$ for NE and 20-100 pg for EPI and DA. Quantification of catecholamine levels was performed by comparing peak height ratios of plasma catecholamines/DHBA vs the standard catecholamine/DHBA ratio according to the following formula:

$($ Conc. UNK $)=\frac{(\text { Cat } / \text { DHBA }) \text { UNK }}{(\text { Cat } / \text { DHBA }) \text { KNOWN }} \times($ Conc. Cat $)$ KNOWN

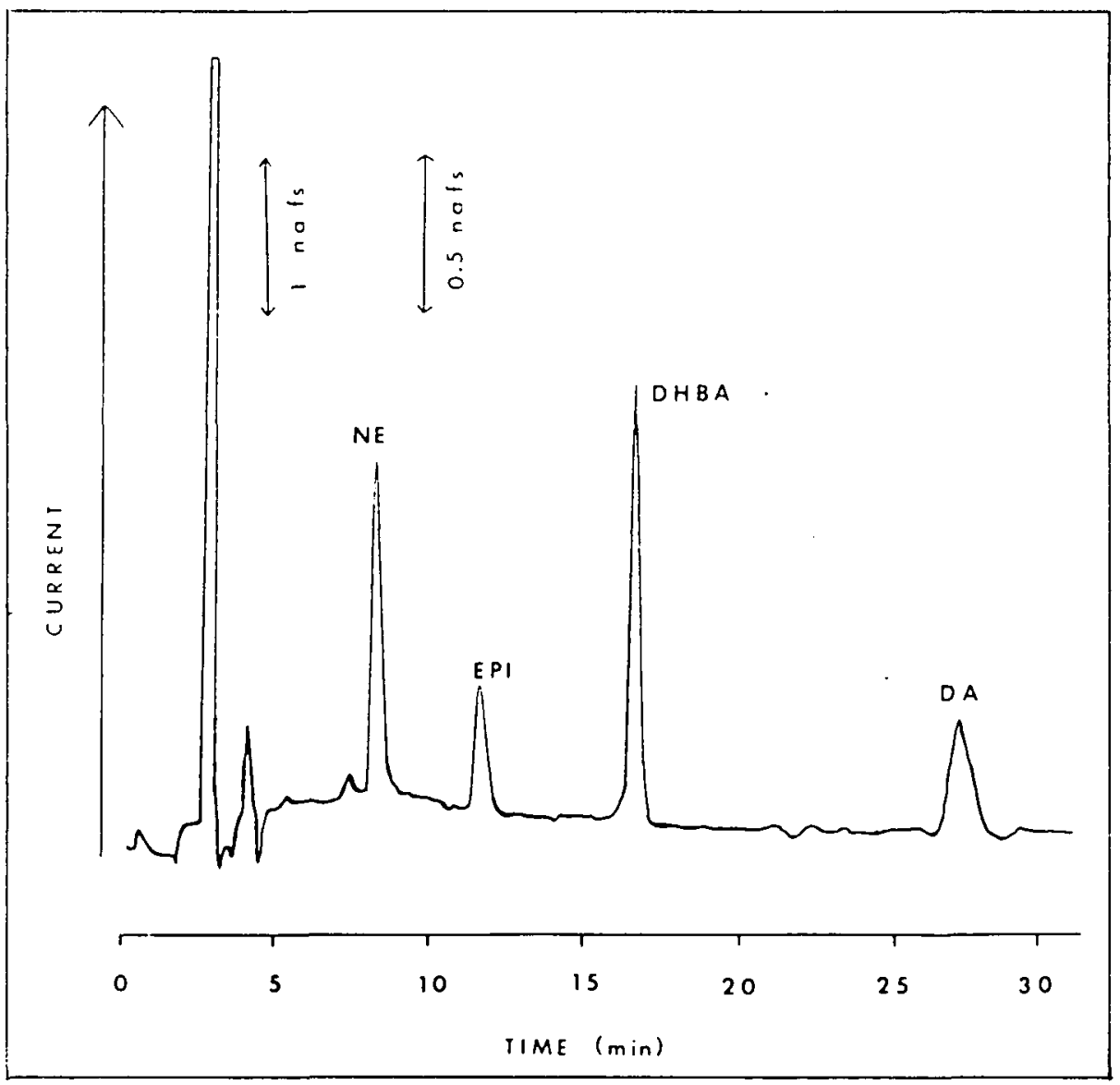

Figure 1 - Chromatogram resulting from injection of standard catecholamine mixture representing $120 \mathrm{pg} \mathrm{NE}, 60 \mathrm{pg}$ EPI and $60 \mathrm{pg}$ DA. 
This was then adjusted for the recovery and the amount of plasma extract actually analyzed. Differences between group means were analyzed by means of unpaired t-tests.

\section{RESULTS AND DISCUSSION Chromatographic Separation}

Figure 1 represents the chromatogram of a standard catecholamine mixture taken through the assay and injected on the column. The amounts injected were $120 \mathrm{pg} \mathrm{NE}$, $50 \mathrm{pg}$ EPI and $50 \mathrm{pg}$ DA. As can be seen from the figure no contaminating peaks elute with the catecholamines standards to interfere with the assay. Figure 2 represents the chromatogram obtained with a plasma sample, NE, $172.2 \mathrm{pg} / \mathrm{ml}$; EPI, $79.9 \mathrm{pg} / \mathrm{ml}$ and DA, $34.1 \mathrm{pg} / \mathrm{ml}$. Together with these catecholamines other peaks can also be seen. Due to the characteristics of alumina extraction and the fact that these peaks must represent oxidizable compounds, the range of possible substances represented by these peaks is limited. In all likelihood these peaks are precursors and/or metabolites of NE and DA. We are now in the process of identifying them.

\section{Method Reliability}

Table 1 compares the catecholamine data obtained using LCEC to the data obtained using either the single or double isotope radioenzymatic assay. In all cases plasma was drawn from normal subjects while in a supine position.

Clearly, under these conditions, catecholamine levels measured with LCEC accord well with those measured using the radioenzymatic assay. Furthermore, it seems that the detection and quantification of dopamine using radioenzymology is not always reliable due to high blank values (Weise and Kopin, 1976). However, using the method described

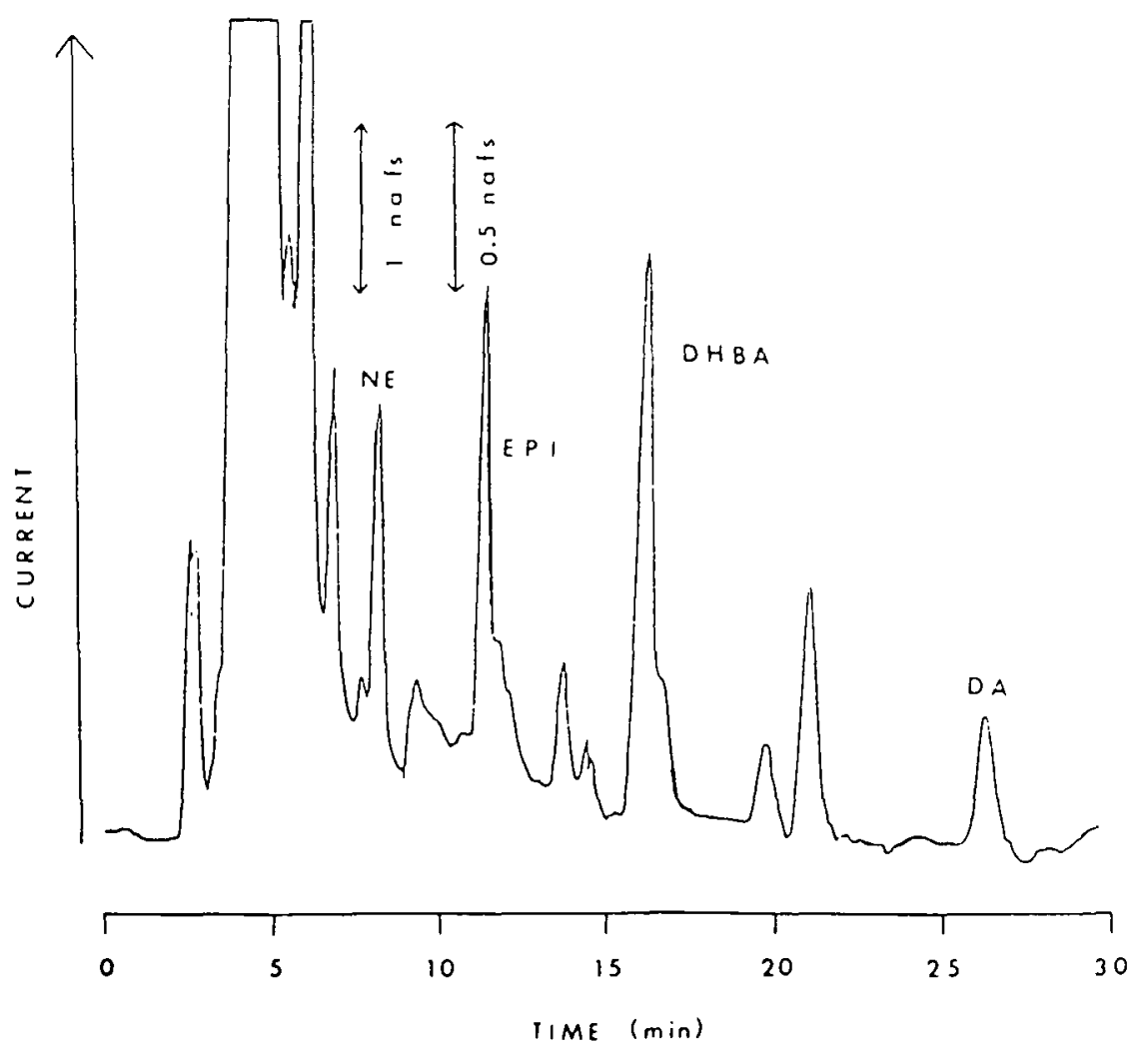

Figure 2 - Chromatogram obtained from the injection of $100 \mu 1$ of human plasma extract. above, dopamine is readily resolved and, in our experience accurately quantifiable.

\section{Catecholamine Levels in Patients vs Controls}

The results of this study confirm in most parts the findings of increased free catecholamine levels in plasma of patients with Friedreich's ataxia (Pasternak et al, 1982). As can be seen in Figure 3, norepinephrine and dopamine levels were significantly higher in plasma of ataxics than in controls $(\mathrm{t}(15)=1.95 ; \mathrm{p}<0.05 ;$ and $(\mathrm{t}(15)$ $=3.30, p<0.01)$ respectively. While epinephrine was also elevated, this increase did not reach statistical significance $(t(15)=1.38, p>0.05)$. Finally, total plasma catecholamines $(\mathrm{NE}+\mathrm{EPI}+\mathrm{DA})$ were also significantly greater in patients than in controls $(t(15)=2.26, p<0.02)$.

That these results do not reach the same significance value for epinephrine as those reported by Pasternak et al, (1982) might be due to the smaller number of patients tested by us. Moreover, the degree of cardiomyopathy in our patients was not assessed at the time of catecholamine determination. Thus it is possible that our group represents a less homogeneous population than does the group tested by Pasternak et al, (1982), all of whom displayed some degree of cardiac involvement. The increased dopamine found in plasma of our patients, a result first reported here, might reflect the better sensitivity of the present method to detect low circulating levels of this catecholamine.

The observation of increased catecholaminergic activity in Friedreich's Ataxia is of importance, but still difficult to explain. Most of the physiological possibilities have already been discussed in Dr. Pasternak's paper (1982, this issue) and indicate that increased synaptic release particularly of norepinephrine, could account for the development and the maintenance of the cardiomyopathy. However, the possibility of increased secretion is far from proven. One must also consider the alternative of a disturbance at the level of post-synaptic membrane, particularly the receptor 


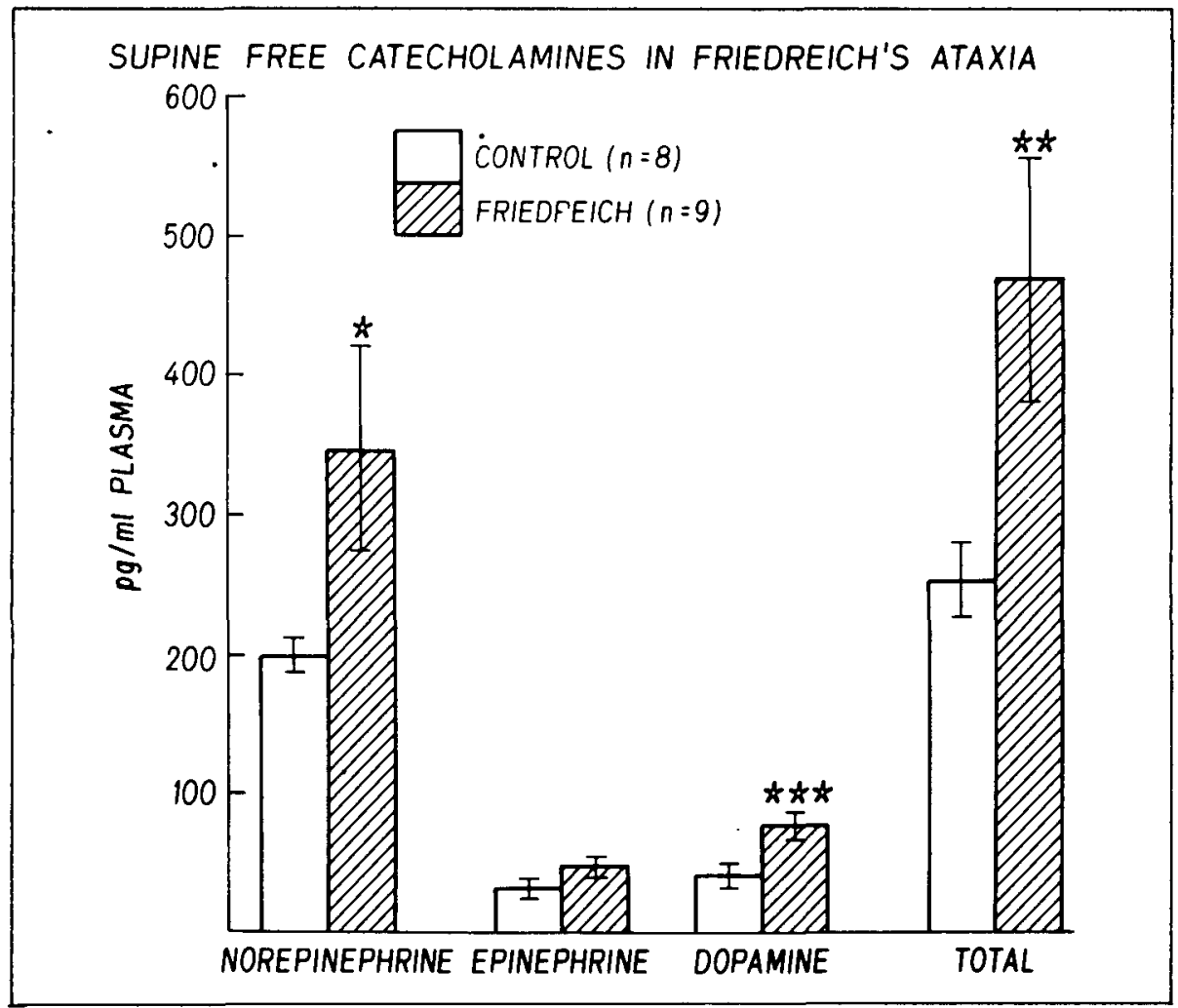

Figure 3 - Levels of free NE, EPI, DA and total plasma catecholamines $(\mathrm{pg} / \mathrm{ml})$ in patients with

Friedreich's Ataxia (Striped bars) vs control (open bars). Results are expressed as Mean \pm S.E.M.

* Significantly different from controls, $\mathrm{p}<0.05$

** Significantly different from controls, $p<0.02$

*** Significantly different from controls, $\mathrm{p}<0.01$

portion of these membranes, or even within the effector cells, such as within the second messenger generating system. Data exists to support both these possibilities. Modifications in the concentration of membrane linoleic acid (18:2), such as those reported by Huang et al (1980) in Friedreich's Ataxia, could reduce the reactivity and sensitivity of certain adrenergic receptors, thereby modifying the turnover of the catecholamines. Findings to be reported in this issue (Barbeau, et al, 1982) concerning taurine transport, could be reflected in abnormal calcium concentrations within the post synaptic membranes, thereby modifying the hormonal response mechanism. Only further experimentation will help resolve these questions.

\section{ACKNOWLEDGMENTS}

The studies reported in this paper were supported by grants from l'Association Canadienne de l'Ataxie de Friedreich and the $O$. Malette Foundation of the Hôtel-Dieu Hospital. Thanks are due to Mrs. Hélène $L$. Crête for typing the manuscript.

\section{REFERENCES}

ANGELAKOS, E.T., CARBALLO, L.C., DANIELO, J.B., KING, M.P., and BAJUSZ, E. (1972) Adrenergic neurohumors in the heart of hamsters with hereditary myopathy during cardiac hypertrophy and failure. In: Recent Advances in Studies on Cardiac Structure and Metabolism. Vol. I Myocardiology, edited by E. Bajusz and G. Rona. Univ. Park Press, Baltimore, pp. 262278.

ANTON, A.H. and SAYRE, D.F. (1962) A study of the factors affecting the aluminum oxide-trihydroxyindole procedure for the analysis of catecholamines. J. Pharmac. Exp. Ther. 138: 360-375.

COTE, M., DAVIGNON, A., PECKODROUIN, N., SOLIGNAC, A., GEOFFROY, G., LEMIEUX, B. and BARBEAU, A. (1976) Cardiological signs and symptoms in Friedreich's Ataxia. Can. J. Neurol. Sci. 3: 319-322.

ENGLEMAN, K., PORTNAY, B. and LOVENBERG, W. (1968) A sensitive and specific double isotope derivative method for the determination of catecholamines in biological specimens. Am. J. Med. Sci. 255: 259-268.
FENN, R.J., SIGGIA, S. and CURRON, D.J. (1978) Liquid chromatography detector based on single and turn electrode thin-layer electrochemistry: application to the determination of catecholamines in blood plasma. Anal. Chem. 50: 1067-1073.

GAZES, P.C., RICHARDSON, J.A. and WOODS, E.F. (1959) Plasma catecholamine concentrations in myocardial infarction and angina pectoris. Circulation 19: 657-661.

GEOFFROY, G., BARBEAU, A., BRETON, G., LEMIEUX, B., AUBE, M., LEGER, C. and BOUCHARD, J.P. (1976) Clinical description and Roentgenologic evaluation of patients with Friedreich's Ataxia. Can. J. Neurol. Sci. 3: 279-286.

GOLDSTEIN, D.S., FEUERSTEIN, G., LZZO, J.L., KOPIN, I.J. and KEISER, H.R. (1981) Validity and reliability of liquid chromatography with electrochemical detection for measuring plasma levels of norepinephrine and epinephrine in man. Life Sci. 28:467-475.

HJEMDAHL, P., DALESKOG, $M$, and KAHAN, T. (1979) Determination of plasma catecholamines by High Performance Liquid Chromatography with electrochemical detection: Comparison with a radioenzymatic method. Life Sci. 25: 131138.

HUANG, Y.S., MARCEL, Y.L., VEZINA, C., BARBEAU, A. and DAVIGNON, J. (1980) Lecithin: Cholesterol acyltransferase activity and fatty acid composition of Erythrocyte Phospholipids in Friedreich's Ataxia. Can. J. Neurol. Sci. 7: 429-434.

MALO, S., LATOUR, Y., COTE, M., GEOFFROY, G., LEMIEUX, B. and BARBEAU, A. (1976) Electrocardiographic and vectocardiographic findings in Friedreich's Ataxia. Can. J. Neurol. Sci. 3: 329-332.

PEDERSON, E.B. and CHRISTENSEN, N.J. (1975) Catecholamines in plasma and urine in patients with essential hypertension determined by double isotope derivative techniques. Acta Med. Scand. 198: 373-377.

PEULER, J.D., and JOHNSON, G.A. (1972) Simultaneous single isotope radioenzymatic assay of plasma norepinephrine, epinephrine and dopamine. Life Sci. 21: 625-636.

WEISE, V.K. and KOPIN, I.J. (1976) Assay of catecholamines in human plasma: Studies of a single isotope radioenzymatic technique. Life Sci. 19: 1673-1685.

YOUNG, R.C., THOMAS, M., EVANS, M.E. and OPIE, L.H. (1972) Catecholamines in myocardial infarction. In: Recent Advances in Studies on Cardiac Structure and Metabolism. Vol. I Myocardiology, edited by E. Bajusz and G. Roma. Univ. Park Press, Baltimore, pp. 163-168. 